\title{
The 100-most Cited Articles About Craniectomy and Hemicraniectomy: A Bibliometric Analysis
}

\author{
Eric Whitney ${ }^{1}$, Deependra Mahato ${ }^{1}$, Tiffany Odell ${ }^{1}$, Yasir R. Khan ${ }^{1}$, Javed Siddiqi ${ }^{1}$
}

1. Neurosurgery, Desert Regional Medical Center, Palm Springs, USA

Corresponding author: Deependra Mahato, deependra.mahato@gmail.com

\begin{abstract}
Craniectomy is a life-saving procedure used in the setting of traumatic brain injury ' stroke and increased intracranial pressure. The purpose of this study was to analyze and determine the most influential articles and authors in the field of craniectomy. Our study presents an analysis of the articles that include the word "craniectomy" or "hemicraniectomy" in the title and a detailed analysis of the top 100-cited articles in that selection. This search provided insight into how this procedure was initially documented and how it has been utilized over the years. We used the SCOPUS database to search "craniectomy OR hemicraniectomy" in the article title. We then sorted the top 100 most-cited articles. Bibliometric analysis was performed. An Hindex was presented with each author. The citation count ranged from 71 to 5310 . The most published author was Werner Hacke, a German researcher $(n=6)$. The highest quantity of influential work was published in 2006 and 2007 ( $n=9 / y r)$. The United States published the most articles $(n=42)$. The Journal of Neurosurgery published 21 of the top 100 most-cited articles. The chronological timeline shows the evolution of decompression as it related to both stroke and trauma. It demonstrated that well-cited articles acted as turning points to direct further scientific endeavors while highlighting the hard work of certain authors. There is, to the best of our knowledge, a shortage of literature on a bibliometric analysis regarding the term craniectomy. Thus, the current bibliometric study was undertaken to highlight the work of authors who have advanced knowledge about this procedure. It provides an analysis of the top 100-cited articles with craniectomy in the title with dates ranging from 1892 to 2016 . A review of its publication history shows how interventions in this field have advanced over the last several decades.
\end{abstract}

Received 07/27/2019

Review began 08/05/2019 Review ended 08/14/2019 Published 08/29/2019

๑) Copyright 2019 Whitney et al. This is an open access article distributed under the terms of the Creative Commons Attribution License CC-BY 3.0., which permits unrestricted use, distribution, and reproduction in any medium, provided the original author and source are credited.
Categories: Medical Education, Neurology, Neurosurgery

Keywords: bibliometric analysis, brain trauma, middle cerebral artery infarct, trephination, decompressive hemicraniectomy, craniectomy

\section{Introduction And Background}

A bibliometric analysis is the statistical analysis of written publications. It seeks to quantify the academic output of people and institutions. In the strictest sense, it is an effort to present an assessment of the scientific literature of a given topic. Understanding the publication data of a topic lends insight into the current state of that field and identifies those authors who have made the greatest impact.

Craniectomy and hemicraniectomy are decompressive procedures wherein a bone flap is elevated from the skull to relieve intracranial pressure which has been refractory to medical management. The origin of craniectomy can be traced to the Neolithic period (9600 BC to 2000 BC) with the practice of trephination and the placement of burr holes into the cranium for various reasons. In fact, trephination is the earliest surgical procedure for which we have archaeological evidence [1]. Throughout history, craniectomy and hemicraniectomy have been associated with significant morbidity and mortality. Craniectomy has remained one of the most common neurosurgical procedures performed in traumatic brain injury in modern medicine. Nevertheless, the sequelae of increased intracranial pressure including stroke, herniation, and death remain. This procedure has been the target of several large-scale multicenter and single-center trials leading to its development and expansion with regards to determining its rates of morbidity and mortality. These trials include DECRA, DECIMAL, DESTINY I \& II, HAMLET, RESCUEICP and more recently RESCUE-ASDH.

\section{Review}

\section{Methods}

Elsevier's Scopus, a comprehensive abstract and citation database for peer-reviewed literature, was primarily utilized for the collection of information about the publications under the search term "craniectomy" in May 2019. The search was conducted using the terms "craniectomy OR hemicraniectomy" in the article title. This resulted in 1,646 documents. These results were filtered for the top 100 most-cited articles. Using the Scopus analytics tool, we were able to view documents by year, documents per year by source, documents by author, documents by affiliation, documents by country, and documents by funding sponsor. The H index has been included for each top author. Originally proposed by Hirsch, it is a research output measure that represents original research and other publications designed to indicate impact [2]. For example, an $\mathrm{H}$ index value of 22 means that 22 articles have been cited at least 22 times. The 20 most-cited 


\section{Cureus}

articles were selected for an in-depth review.

\section{Results}

The documents by year analysis, from 1892 to 2016 (Figure 1), revealed a paucity of well-cited literature in the early 1900s. In 1892, a document titled, "Pioneer craniectomy for relief of mental instability due to premature sutural closure and microcephalus" was published and has garnered 132 citations to date [3]. In the 100 most-cited articles, there is a large time gap. The 1970s saw eight well-cited documents and outshined the 1980s, which only produced four of the top-cited articles. The 1990s saw a resurgence in publications $(\mathrm{n}=16)$. This trend continued into the 21 st century as most of the top-cited articles were published between 2000 and $2009(\mathrm{n}=57)$. The past nine years have only seen 14 of the most-cited articles published with a dramatic taper from six in 2010 to one in 2016.

Documents by year

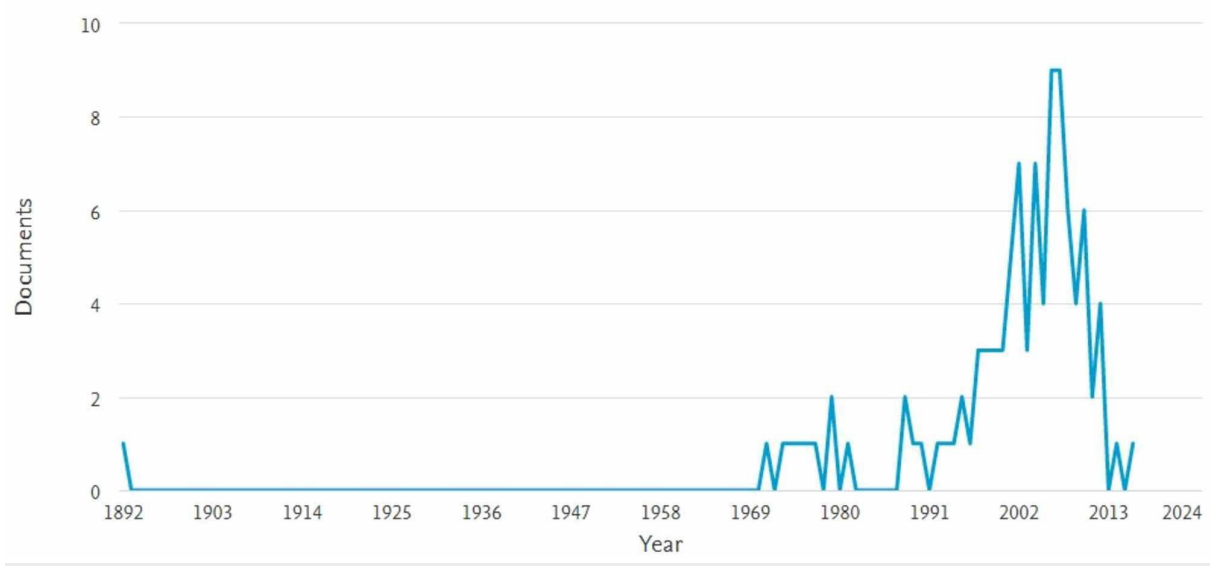

FIGURE 1: Graphs of the documents by year displaying a large growth in the 1990s and early 2000s

The documents by source (Figure 2) analysis starts in 1972. Previous dates did not include the top sources. The Journal of Neurosurgery published 21 articles. The Stroke published 14; Neurosurgery following with 10. The Journal of Neurotrauma published nine and Surgical Neurology published six. These top three journals are responsible for $45 \%$ of the top-cited publications on this topic.

Documents per year by source

Compare sources and view CiteScore, SJR, and SNIP data

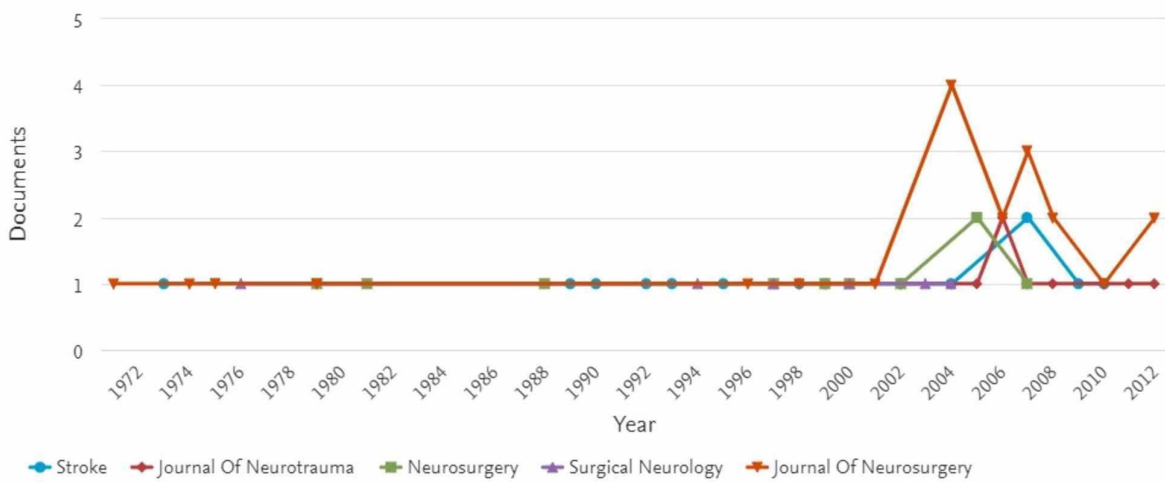

FIGURE 2: The five journals that have published the majority of the topcited articles

The documents by author category compare the publication count within the top 100 most-cited articles of specific authors and their H-index (Figure 3). 


\section{Cureus}

Publications by author

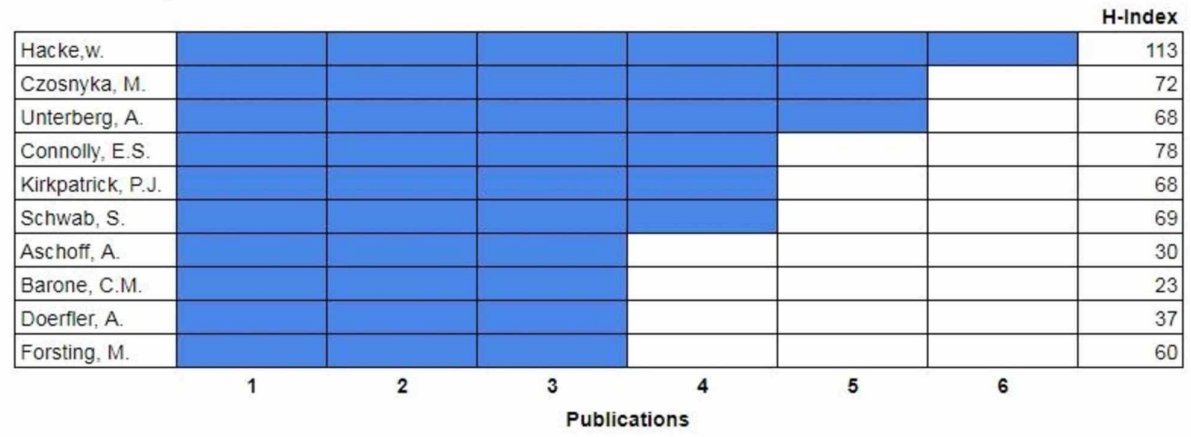

FIGURE 3: Authors responsible for the influencing the field

The top-ranked author was Werner Hacke who published six of the most-cited articles. His most-cited article, "Early hemicraniectomy in patients with complete middle cerebral artery infarction" was published in 1998 and cited 552 times [4]. Two authors tied with five publications each: Czosnyka and Unterberg. Czosnyka's paper, "Trial of decompressive craniectomy for traumatic intracranial hypertension", was published in 2016 and has been cited 237 times [5]. Unterberg's article, "Hemicraniectomy in older patients with extensive middle-cerebral-artery stroke" was published in 2014 and has been cited 244 times [6]. Connolly, Kirkpatrick, and Schwab have each contributed four articles. Aschoff, Barone, Doerfler, Forsting, Hutchinson, Jimenez each contributed three articles.

The top authors were found to work in teams. The top-ranked author, Hacke, worked with the other wellranked authors, namely, Doerfler, Forsting, Unterberg, and Schwab. Their work focused on craniectomy in the setting of stroke and encephalitis [4, 6-10]. Czosnyka worked with Hutchinson and Kickpatrick. Their work focused on decompressive craniectomy in traumatic brain injury and intracranial hypertension $[5,11$ 14]. Unterberg worked with Czosnyka, Hutchinson, and Kirkpatrick. Their publications from 20012016 focused on hemicraniectomy while considering intracranial hypertension, stroke, trauma, and functional outcomes $[5-6,11,15-16]$. Connolly was not published with the other top 10 authors (20022007). His worked highlighted hemicraniectomy in the setting of subarachnoid hemorrhage and infarctions [17-20]. Kirkpatrick worked with Czosnyka and Hutchinson (previously mentioned above) on publications from 2001 to 2016 and was affiliated with Addenbrooke Hospital and the University of Cambridge [5, 11, 1314]. Schwab worked with Hacke and Aschoff producing works from 1997-2002 out of the University of Heidelberg [4, 10, 21-22]. Barone worked with Jimenez. His works, 1998-2004, focused on craniosynostosis and were affiliated with the University of Missouri-Columbia [23-25]. Doerfler worked with Forsting and produced top works from 1996-2002 in relationship to decompression in MCA stroke from the University of Heidelberg [7, 26-27].

The publications by affiliation category shows which institutions have produced the research (Figure 4). The University of California, San Francisco and its school of medicine produced 12 publications. The University of Heidelberg produced nine works [4-8, 10, 21-22, 28]. Addenbrooke's Hospital produced five works [5, 1114]. Charite Universitatsmedizin Berlin had four works. The University of Missouri-Columbia and LudwigMaximilians Universitat Munchen had three publications apiece [6, 15-16, 29].

\section{Publications by affiliation}

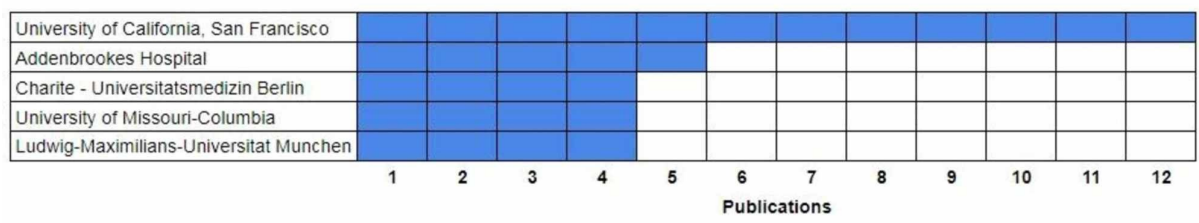

FIGURE 4: Listing of top institutions

The United States contributed $42 \%$ of the literature on the topic, followed by Germany at 21\%, and then United Kingdom at 8\% (Figure 5). 


\section{Cureus}

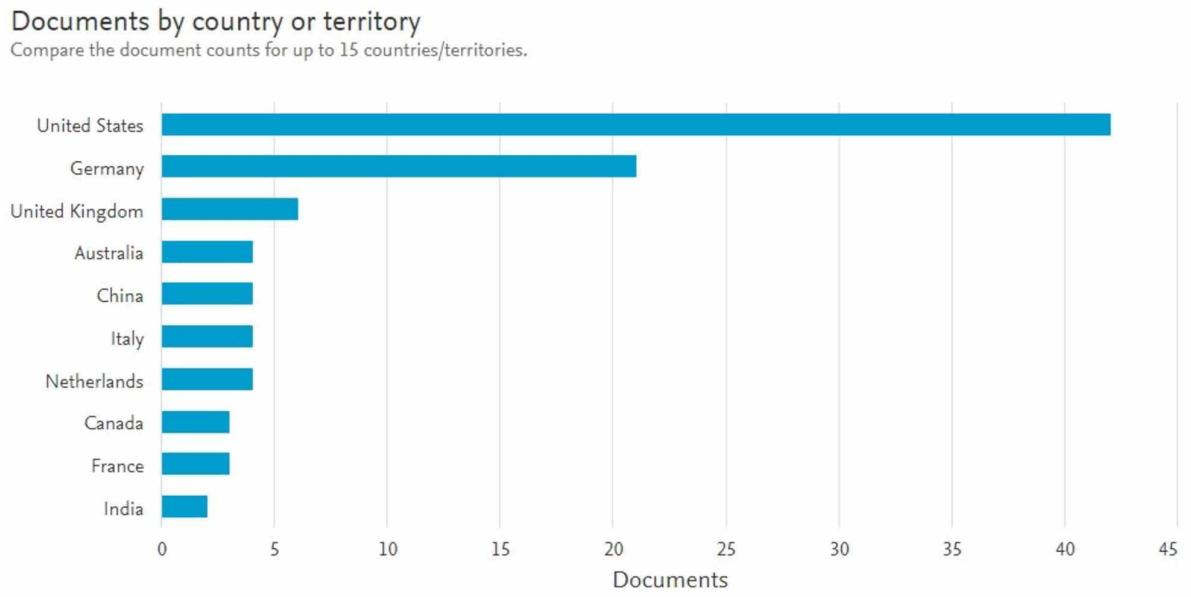

\section{FIGURE 5: Graph showing the countries which produced the top}

articles

The documents according to funding sponsors had three top contributions. Each entity had one publication. The work sponsored by Capital Foundation of Medical Development, a Chinese company, was cited 72 times [30]. The work by Deutsche Forschungsgemeinschaft, who funds medical research in Germany, was cited 245 times [6]. Medical Research Council, who coordinates medical research in the UK, had their article cited 237 times [5].

\section{Discussion}

The craniectomy procedure is a foundation of neurosurgical practice. Archaeological evidence of skulls from the Neolithic period demonstrating trephination, the ancient technique of burr holing (see Figure 6), make craniectomy the earliest surgical procedure recorded in history [1]. As surgical tools improved, the procedure also morphed from simple trephination into what is now known as craniectomy/craniotomy. In 1518, Berengario da Capri published a manuscript that describes both the indications and technique for craniotomy [31]. 


\section{Cureus}

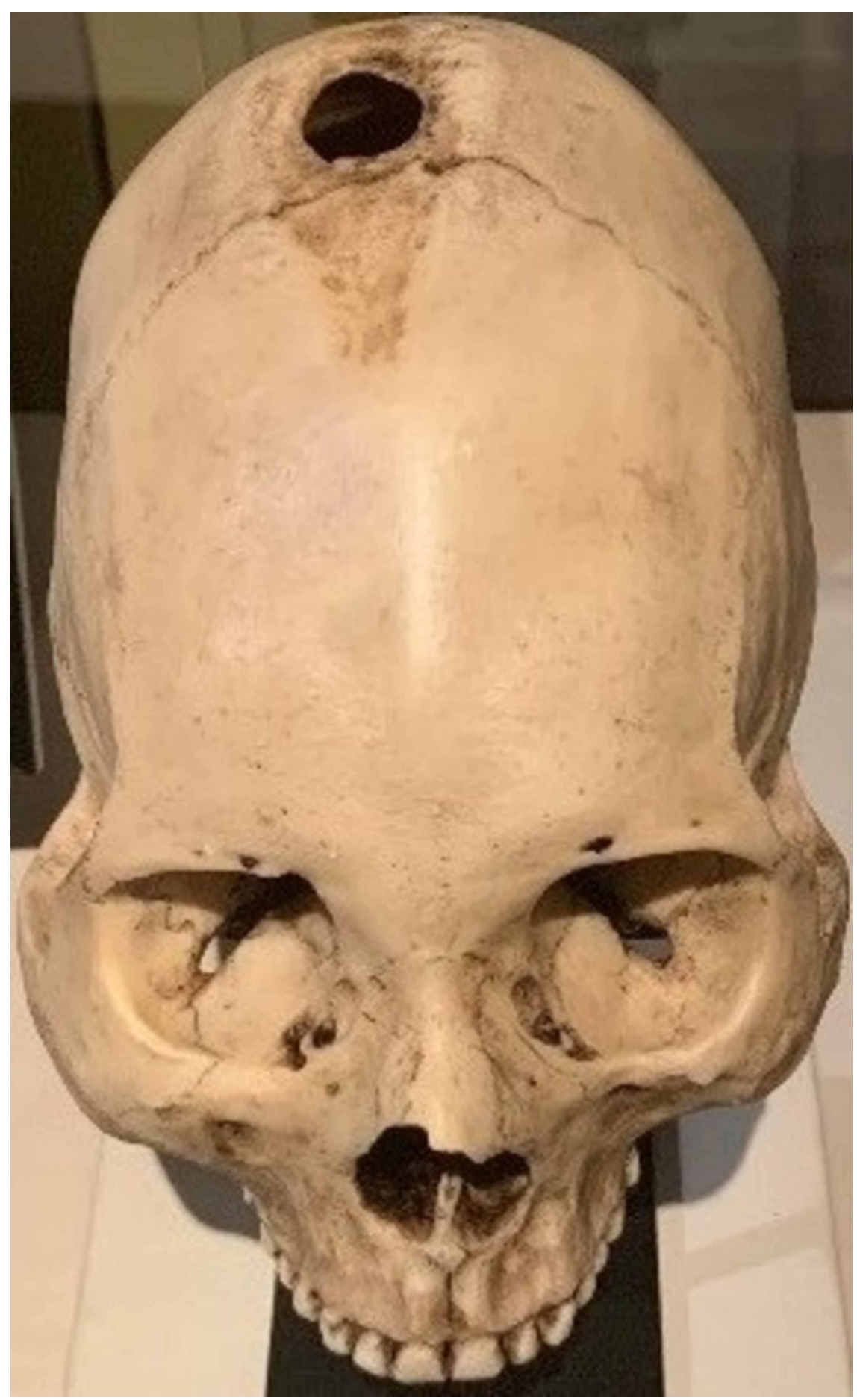

FIGURE 6: Photograph taken at the Houston Museum of Natural Science in June 2019 showing an early form of trephination

Photo credit: Eric Whitney

In 1892, Lane published a case series entitled "Pioneer craniectomy for relief of mental imbecility due to premature sutural closure and microcephaleus". In his brief article, he explains the circumstances under which he tried to "unlock the brain" of a 9-month-old. This child died 14 hours after the procedure due to anesthetic complications. A second patient from another case detailed in the same report was thriving at the time of his writing in 1892 [3]. There is a time gap from 1892 to 1971 where articles on these subjects did not make the list of top 100 most cited. After 1971, there was a noted emphasis on the application and development of craniectomy and are therefore highlighted in chronological order up until 1998, after which the publication load increased and the topic began to answer more specific questions. 
In 1971, Ransohoff published his pioneering work on the use of hemicraniectomy in the management of acute subdural hematoma $(n=35)$ in the Journal of Neurosurgery. He reported a $40 \%$ survival and $28 \%$ return to normal function. His results were outstanding for the time [32]. Subsequent utilization of the intervention failed to reproduce equivalent results and, in 1976, Cooper published (in Surgical Neurology) that in the five years proceeding Ransohoff's paper only 50 patients were reported to be treated with decompressive craniotomy. Cooper reports a dismal $10 \%$ percent survival and $4 \%$ to function. He called for a move to restrict the utilization of the procedure [33]. Five years later (1981) in Neurosurgery

Journal, Rengachary published a report of three patients treated with hemicraniectomy for "massive multilobar infarction [...] who survived, although severe fixed neurological deficit persisted in two" [34]. In 1988, Kondziolka, citing Rengachary’s 1981 publication, reported on five patients who were permitted to progress to "uncal herniation and pending death" prior to surgery, achieved "good results" status post "decompressive craniectomy in the treatment of lesions causing increased intracranial pressure and brain edema” [35].

Delashaw argued in his 1990 Stroke publication based on a sample of nine that "hemicraniectomy can be an effective life-saving procedure for malignant cerebral edema after large hemispheric infarction” [36]. The year 1992 saw the advent of the first well-cited article on successful suboccipital craniectomy by Chen in Stroke [37]. In 1994 Fisher, in Surgical Neurology, published a case report discussing craniectomy in a comatose woman who suffered from a SAH [38]. By the mid-1990s, Hacke, Doerfler, Schwab, and Forsting were publishing high-ranking articles laying the groundwork for the trials of the 2000s (Table 1) [7-8, 10]. In 1995, Forsting published "Decompressive craniectomy for cerebral infarction: An experimental study in rats", which showed that decompression reduced mortality in rats and called upon neurosurgical intervention for this population. In 1997, Polin showed that "decompressive bifrontal craniectomy provides a statistical advantage over medical treatment of intractable posttraumatic cerebral hypertension and should be considered in the management of malignant post-traumatic cerebral swelling. If the operation can be accomplished before the ICP value exceeds 40 torr for a sustained period and within 48 hours of the time of injury, the potential to influence outcome is greatest [39]".

Trial Name

DECIMAL (2007): decompressive craniectomy in malignant middle cerebral artery infarction trial. They concluded in a population age $18-55$ and $\mathrm{N}=38$ an increase in moderate disability and a decrease in mortality when compared to medical therapy.

DESTINY (2007): decompressive surgery for the treatment of malignant infarction of the middle cerebral artery. It showed that there was a significant reduction in 30-day mortality for decompression as opposed to medical management.

HAMLET (2009): hemicraniectomy after middle cerebral artery infarction with life-threatening edema trial. They introduced a four-day window for surgical intervention $(\mathrm{N}=64)$. They concluded, "Surgical decompression reduces case fatality and poor outcome in patients with space-occupying infarctions who are treated within 48 hours of stroke onset. There is no evidence that this operation improves functional outcome when it is delayed for up to $96 \mathrm{~h}$ after stroke onset".

DECRA (2011): bifrontal temporoparietal decompressive craniectomy in diffuse traumatic brain injury for patients with refractory elevation in ICP was associated with decreased ICP but a higher incidence of overall morbidity.

DESTINY II (2014): Hemicraniectomy in older patients with extensive middle-cerebral-artery stroke.

RESCUEicp (2016): The trial of randomized evaluation of surgery with craniectomy for uncontrollable elevation of intracranial pressure after initial medical management was associated with lower mortality than medical management alone. Return of function with a need for higher level of dependent care was worse in the surgical group.

RESCUE-ASDH (2019) - Randomized evaluation of surgery with craniectomy for patients undergoing evacuation of acute subdural hematoma trial. Recently closed enrolment on May 1, 2019 after reaching the goal of 463 randomized patients

\section{TABLE 1: This lists the clinical trials related to decompressive craniectomy}

DECIMAL: decompressive craniectomy in malignant middle cerebral artery infarction; DESTINY: decompressive surgery for the treatment of malignant infarction of the middle cerebral artery; HAMLET: hemicraniectomy after middle cerebral artery infarction with life-threatening edema trial; DECRA: decompressive craniectomy trial; RESCUEicp: Randomized evaluation of surgery with craniectomy for uncontrollable elevation of intracranial pressure; RESCUE-ASDH: Randomized evaluation of surgery with craniectomy for patients undergoing evacuation of acute subdural hematoma

in 1998, Jimenez published, in the Journal of Neurosurgery, the article "Endoscopic craniectomy for early surgical correction of sagittal craniosynostosis". His four-case study report highlighted a decrease in blood loss, operative time, and cost with excellent surgical results [24]. That same year Schwab published "Early hemicraniectomy in patients with complete middle cerebral artery infarction". They stated that not only did craniectomy improve outcomes but also that early craniectomy (first 24 hours after onset of stroke) further 
improved outcomes [4]. In 2001, Holkamp published "Hemicraniectomy in elderly patients with spaceoccupying media infarction: Improved survival but poor functional outcome". They concluded that a large trial was needed to prove benefit [15].

Over the next 20 years, two major themes dominated. The first was decompression in the setting of infarction, and the second was decompression in the setting of trauma and increased intracranial pressure. Large clinical trials were undertaken to review the effectiveness of craniectomy (Table 1). Correlating to the published results of these trials is a large increase in year-by-year publications with the term in the title going from 42 papers in 2006 to 120 papers in 2016. Finally, in 2014 Juttler published DESTINY II, "Hemicraniectomy in older patient with extensive MCA stroke, to address the age limitations of previous trials". They concluded that hemicraniectomy improved the survival rates without severe disability in those 61 and older [6].

\section{Limitations}

All the top-100 articles with the term in the title were analyzed. However, it is difficult to ascertain which articles may have impacted the field but were simply not analyzed due to both search term limitations and the terms themselves. The ranking is subject to change as new publications are made available.

\section{Conclusions}

In this bibliometric analysis, we identified the top 100 most-cited articles with the term "craniectomy OR hemicraniectomy" in the title. The data presented shows the top contributors to the field and a chronological timeline in the evolution of these interventions by focusing on the articles that paved the way for clinical trials and more focused research.

\section{Appendices}

These articles (Table 2) represent turning points and question generators that have helped shape the direction and discussion of the intervention.

\section{Article Title}

Longa EZ, Weinstein PR, Carlson S, Cummins R. Reversible middle cerebral artery occlusion without craniectomy in rats. Stroke. 1989, 20:84-91. 10.1161/01.str.20.1.84

Cooper DJ, Rosenfeld JV, Murray L, et al.: Decompressive craniectomy in diffuse traumatic brain injury. N Engl J Med. 2011, 364:1493-1502. 10.1056/NEJMoa1102077

3 Schwab S, Steiner T, Aschoff A, Schwarz S, Steiner HH, Jansen O, Hacke W: Early hemicraniectomy in patients With complete middle cerebral artery infarction. Stroke. 1998, 29:1888-1893. 10.1161/01.str.29.9.1888

Jüttler E, Schwab S, Schmiedek P, Unterberg A, Hennerici M, Woitzik J, Witte S, Jenetzky E, Hacke W: Decompressive

4 surgery for the treatment of malignant infarction of the middle cerebral artery (DESTINY). Stroke. 2007, 38:2518-2525. 10.1161/strokeaha.107.485649

Hofmeijer J, Kappelle LJ, Algra A, Amelink GJ, van Gijn J, van der Worp HB: Surgical decompression for space-

5 occupying cerebral infarction (the Hemicraniectomy After Middle Cerebral Artery infarction with Life-threatening Edema Trial [HAMLET]): a multicentre, open, randomised trial. Lancet Neurol. 2009, 8:326-333. 10.1016/s1474-4422(09)70047-x

Vahedi K, Vicaut E, Mateo J, et al.: Sequential-design, multicenter, randomized, controlled trial of early decompressive

6 craniectomy in malignant middle cerebral artery infarction (DECIMAL Trial). Stroke. 2007, 38:2506-2517. 10.1161/strokeaha.107.485235

Polin RS, Shaffrey ME, Bogaev CA, Tisdale N, Germanson T, Bocchicchio B, Jane JA: Decompressive bifrontal

7 craniectomy in the treatment of severe refractory posttraumatic cerebral edema. Neurosurgery. 1997, 41:84-94. 10.1097/00006123-199707000-00018

8 Aarabi B, Hesdorffer DC, Ahn ES, Aresco C, Scalea TM, Eisenberg HM: Outcome following decompressive craniectomy for malignant swelling due to severe head injury. J Neurosurg. 2006, 104:469-479. 10.3171/jns.2006.104.4.469

Taylor A, Butt W, Rosenfeld J, Shann F, Ditchfield M, Lewis E, Klug G, Wallace D, Henning R, Tibballs J: A randomized

9 trial of very early decompressive craniectomy in children with traumatic brain injury and sustained intracranial hypertension. Childs Nerv Syst. 2001, 17:154-162. 10.1007/s003810000410

10

Sahuquillo J: Decompressive craniectomy for the treatment of refractory high intracranial pressure in traumatic brain injury. Cochrane Database Syst Rev. 2006. 10.1002/14651858.CD003983.pub2

Gupta R, Connolly ES, Mayer S, Elkind MSV: Hemicraniectomy for massive middle cerebral artery territory Infarction. 


\section{Cureus}

11 Stroke. 2004, 35:539-543. 10.1161/01.str.0000109772.64650.18

Jüttler E, Unterberg A, Woitzik J, et al.: Hemicraniectomy in older patients with extensive middle-cerebral-artery Stroke.

Münch E, Horn P, Schürer L, Piepgras A, Paul T, Schmiedek P: Management of severe traumatic brain injury by decompressive craniectomy. Neurosurgery. 2000, 47:315-323. 10.1097/00006123-200008000-00009

Hutchinson PJ, Kolias AG, Timofeev IS, et al.: Trial of decompressive craniectomy for traumatic intracranial

hypertension. N Engl J Med. 2016, 375:1119-1130. 10.1056/NEJMoa1605215

Delashaw JB, Broaddus WC, Kassell NF, et al.: Treatment of right hemispheric cerebral infarction by hemicraniectomy.

Hutchinson PJ, Corteen E, Czosnyka M, et al.: Decompressive craniectomy in traumatic brain injury: the randomized

16 multicenter RESCUEicp study (www.RESCUEicp.com). Brain Edema XIII. Acta Neurochirurgica Supplementum. Hoff JT, Keep RF, Xi G, Hua Y (ed): Springer, Vienna; 2006. 96:17-20. 10.1007/3-211-30714-1_4

Gooch MR, Gin GE, Kenning TJ, German JW: Complications of cranioplasty following decompressive craniectomy:

18 analysis of 62 cases. Neurosurg Focus. 2009, 26. 10.3171/2009.3.focus0962

Albanèse J, Leone M, Alliez J-R, Kaya J-M, Antonini F, Alliez B, Martin C: Decompressive craniectomy for severe

19 traumatic brain injury: Evaluation of the effects at one year*. Crit Care Med. 2003, 31:2535-2538. 10.1097/01.ccm.0000089927.67396.f3

Yang XF, Wen L, Shen F, Li G, Lou R, Liu WG, Zhan RY: Surgical complications secondary to decompressive

20 craniectomy in patients with a head injury: a series of 108 consecutive cases. Acta Neurochir (Wien). 2008, 150:12411248. 10.1007/s00701-008-0145-9

\section{TABLE 2: Top 20 most-cited articles}

\section{Additional Information \\ Disclosures}

Conflicts of interest: In compliance with the ICMJE uniform disclosure form, all authors declare the following: Payment/services info: All authors have declared that no financial support was received from any organization for the submitted work. Financial relationships: All authors have declared that they have no financial relationships at present or within the previous three years with any organizations that might have an interest in the submitted work. Other relationships: All authors have declared that there are no other relationships or activities that could appear to have influenced the submitted work.

\section{References}

1. Trephination. (2013). Accessed: August 4, 2019: https://www.ancient.eu/Trephination/.

2. Nowak JK, Lubarski K, Kowalik LM, Walkowiak J: H-index in medicine is driven by original research . Croat Med J. 2018, 59:25-32. 10.3325/cmj.2018.59.25

3. Lane LC: Pioneer craniectomy for relief of mental imbecility due to premature sutural closure and microcephalus. JAMA. 1892, XVIII:49-50. 10.1001/jama.1892.02411060019001f

4. Schwab S, Steiner T, Aschoff A, Schwarz S, Steiner HH, Jansen O, Hacke W: Early hemicraniectomy in patients with complete middle cerebral artery infarction. Stroke. 1998, 29:1888-1893. 10.1161/01.str.29.9.1888

5. Hutchinson PJ, Kolias AG, Timofeev IS, et al.: Trial of decompressive craniectomy for traumatic intracranial hypertension. N Engl J Med. 2016, 375:1119-1130. 10.1056/NEJMoa1605215

6. Jüttler E, Unterberg A, Woitzik J, et al.: Hemicraniectomy in older patients with extensive middle-cerebralartery stroke. N Engl J Med. 2014, 370:1091-1100. 10.1056/NEJMoa1311367

7. Doerfler A, Forsting M, Reith W, et al.: Decompressive craniectomy in a rat model of "malignant" cerebral hemispheric stroke: experimental support for an aggressive therapeutic approach. J Neurosurg. 1996, 85:853-859. 10.3171/jns.1996.85.5.0853

8. Forsting M, Reith W, Schäbitz W-Rd, Heiland S, von Kummer Rd, Hacke W, Sartor K: Decompressive craniectomy for cerebral infarction. Stroke. 1995, 26:259-264. 10.1161/01.str.26.2.259

9. Hofmeijer J, Amelink GJ, Algra A, van Gijn J, Macleod MR, Kappelle LJ, van der Worp HB: Hemicraniectomy after middle cerebral artery infarction with life-threatening Edema trial (HAMLET). Protocol for a randomised controlled trial of decompressive surgery in space-occupying hemispheric infarction. Trials. 2006, 7:10.1186/1745-6215-7-29

10. Schwab S, Junger E, Spranger M, Dorfler A, Albert F, Steiner HH, Hacke W: Craniectomy: An aggressive treatment approach in severe encephalitis. Neurology. 1997, 48:412-417. 10.1212/wnl.48.2.412 
11. Hutchinson PJ, Corteen E, Czosnyka M, et al.: Decompressive craniectomy in traumatic brain injury: the randomized multicenter RESCUEicp study (www.RESCUEicp.com). Brain Edema XIII. Acta Neurochirurgica Supplementum. Hoff JT, Keep RF, Xi G, Hua Y (ed): Springer, Vienna; 2006. 96:17-20. 10.1007/3-211-30714$1 \_4$

12. Timofeev I, Czosnyka M, Nortje J, Smielewski P, Kirkpatrick P, Gupta A, Hutchinson P: Effect of decompressive craniectomy on intracranial pressure and cerebrospinal compensation following traumatic brain injury. J Neurosurg. 2008, 108:66-73. 10.3171/jns/2008/108/01/0066

13. Timofeev I, Kirkpatrick PJ, Corteen E, et al.: Decompressive craniectomy in traumatic brain injury: outcome following protocol-driven therapy. Brain Edema XIII. Acta Neurochirurgica Supplementum. Hoff JT, Keep RF, Xi G, Hua Y (ed): Springer, Vienna; 2006. 96:11-16. 10.1007/3-211-30714-1_3

14. Whitfield PC, Patel H, Hutchinson PJA, et al.: Bifrontal decompressive craniectomy in the management of posttraumatic intracranial hypertension. Br J Neurosurg. 2009, 15:500-507. 10.1080/02688690120105110

15. Holtkamp M: Hemicraniectomy in elderly patients with space occupying media infarction: improved survival but poor functional outcome. J Neurol Neurosurg Psychiatry. 2001, 70:226-228.

10.1136/jnnp.70.2.226

16. Schneider GH, Bardt T, Lanksch WR, Unterberg A: Decompressive craniectomy following traumatic brain injury: ICP, CPP and neurological outcome. Intracranial Pressure and Brain Biochemical Monitoring. Acta Neurochirurgica Supplements. Czosnyka M, Pickard JD, Kirkpatrick PJ, Smielewski P, Hutchinson P (ed): Springer, Vienna; 2002. 81:77-79. 10.1007/978-3-7091-6738-0_20

17. D'Ambrosio AL, Sughrue ME, Yorgason JG, et al.: Decompressive hemicraniectomy for poor-grade aneurysmal subarachnoid hemorrhage patients with associated intracerebral hemorrhage: clinical outcome and quality of life assessment. Neurosurgery. 2005, 56:12-20. 10.1227/01.neu.0000144820.38439.63

18. Gupta R, Connolly ES, Mayer S, Elkind MSV: Hemicraniectomy for massive middle cerebral artery territory infarction. Stroke. 2004, 35:539-543. 10.1161/01.str.0000109772.64650.18

19. Smith ER, Carter BS, Ogilvy CS: Proposed use of prophylactic decompressive craniectomy in poor-grade aneurysmal subarachnoid hemorrhage patients presenting with associated large sylvian hematomas. Neurosurgery. 2002, 51:117-124. 10.1097/00006123-200207000-00018

20. Waziri A, Fusco D, Mayer SA, McKhann GM 2nd, Connolly ES Jr: Postoperative hydrocephalus in patients undergoing decompressive hemicraniectomy for ischemic or hemorrhagic stroke. Neurosurgery. 2007, 61:489-494. 10.1227/01.neu.0000290894.85072.37

21. Georgiadis D, Schwarz S, Aschoff A, Schwab S.: Hemicraniectomy and moderate hypothermia in patients with severe ischemic stroke. Stroke. 2002, 33:1584-1588. 10.1161/01.str.0000016970.51004.d9

22. Wagner S, Schnippering H, Aschoff A, Koziol JA, Schwab S, Steiner T: Suboptimum hemicraniectomy as a cause of additional cerebral lesions in patients with malignant infarction of the middle cerebral artery. J Neurosurg. 2001, 94:693-696. 10.3171/jns.2001.94.5.0693

23. Barone CM, Jimenez DF: Endoscopic craniectomy for early correction of craniosynostosis . Plast Reconstr Surg. 1999, 104:1965-1973. 10.1097/00006534-199912000-00003

24. Jimenez DF, Barone CM: Endoscopic craniectomy for early surgical correction of sagittal craniosynostosis . J Neurosurg. 1998, 88:77-81. 10.3171/jns.1998.88.1.0077

25. Jimenez DF, Barone CM, McGee ME, Cartwright CC, Baker CL: Endoscopy-assisted wide-vertex craniectomy, barrel stave osteotomies, and postoperative helmet molding therapy in the management of sagittal suture craniosynostosis. J Neurosurg. 2004, 100:407-417. 10.3171/ped.2004.100.5.0407

26. Engelhorn T, Doerfler A, Kastrup A, Beaulieu C, Alexander de C, Forsting M, Moseley ME: Decompressive craniectomy, reperfusion, or a combination for early treatment of acute "malignant" cerebral hemispheric stroke in rats?. Stroke. 1999, 30:1456-1463. 10.1161/01.str.30.7.1456

27. Leonhardt G, Wilhelm H, Doerfler A, et al.: Clinical outcome and neuropsychological deficits after right decompressive hemicraniectomy in MCA infarction. J Neurol. 2002, 249:1433-1440. 10.1007/s00415-0020875-1

28. Münch E, Horn P, Schürer L, Piepgras A, Paul T, Schmiedek P: Management of severe traumatic brain injury by decompressive craniectomy. Neurosurgery. 2000, 47:315-323. 10.1097/00006123-200008000-00009

29. Uhl E, Kreth FW, Elias B, et al.: Outcome and prognostic factors of hemicraniectomy for space occupying cerebral infarction. J Neurol Neurosurg Psychiatry. 2004, 75:270-274. https://www.ncbi.nlm.nih.gov/pmc/articles/PMC1738890/

30. Zhao J, Su YY, Zhang Y, et al.: Decompressive hemicraniectomy in malignant middle cerebral artery infarct: a randomized controlled trial enrolling patients up to 80 years old. Neurocrit Care. 2012, 17:161-171. 10.1007/s12028-012-9703-3

31. Rossini Z, Nicolosi F, Kolias AG, Hutchinson PJ, De Sanctis P, Servadei F: The history of decompressive craniectomy in traumatic brain injury. Front Neurol. 2019, 10:458. 10.3389/fneur.2019.00458

32. Ransohoff J, Benjamin MV, Gage EL, Epstein F: Hemicraniectomy in the management of acute subdural hematoma. J Neurosurg. 1971, 34:70-76. 10.3171/jns.1971.34.1.0070

33. Cooper PR, Rovit RL, Ransohoff J: Hemicraniectomy in the treatment of acute subdural hematoma: a reappraisal. Surg Neurol. 1976, 5:25-28.

34. Rengachary SS, Batnitzky S, Morantz RA, Arjunan K, Jeffries B: Hemicraniectomy for acute massive cerebral infarction. Neurosurgery. 1981, 8:321-328. 10.1227/00006123-198103000-00004

35. Kondziolka D, Fazl M: Functional recovery after decompressive craniectomy for cerebral infarction . Neurosurgery. 1988, 23:143-147. 10.1227/00006123-198808000-00002

36. Delashaw JB, Broaddus WC, Kassell NF, et al.: Treatment of right hemispheric cerebral infarction by hemicraniectomy. Stroke. 1990, 21:874-881. 10.1161/01.str.21.6.874

37. Chen HJ, Lee TC, Wei CP: Treatment of cerebellar infarction by decompressive suboccipital craniectomy . Stroke. 1992, 23:957-961. 10.1161/01.str.23.7.957

38. Fisher CM, Ojemann RG: Bilateral decompressive craniectomy for worsening coma in acute subarachnoid hemorrhage. Observations in support of the procedure. Surg Neurol. 1994, 41:65-74. 10.1016/00903019(94)90210-0

39. Polin RS, Shaffrey ME, Bogaev CA, Tisdale N, Germanson T, Bocchicchio B, Jane JA: Decompressive 


\section{Cureus}

bifrontal craniectomy in the treatment of severe refractory posttraumatic cerebral edema. Neurosurgery. 1997, 41:84-94. 10.1097/00006123-199707000-00018 